\title{
Hydrogen Trapping in Tungsten: Impact of Helium Irradiation and Thermal Cycling
}

\author{
Mykola Ialovega ${ }^{a, b}$, Elodie Bernard ${ }^{a}$, Régis Bisson ${ }^{b}$, \\ Celine Martin ${ }^{b}$, Ryuichi Sakamoto ${ }^{c}$, Arkadi Kreter ${ }^{d}$, \\ Etienne Hodille ${ }^{e}$, Thierry Angot $^{b}$, Christian Grisolia $^{a}$ \\ ${ }^{a}$ CEA, IRFM, F-13108 Saint Paul-lez-Durance, France \\ ${ }^{b}$ Aix Marseille University, CNRS, PIIM, Marseille, France \\ ${ }^{c}$ NINS, National Institute for Fusion Science, Toki, Gifu 509-5292, Japan \\ ${ }^{d}$ Forschungszentrum Jülich GmbH, Institut für Energie- und \\ Klimaforschung-Plasmaphysik, 52425 Jülich, Germany \\ ${ }^{e}$ University of Helsinki, P.O. Box 33 (Yliopistonkatu 4), 00014 Helsinki, Finland \\ E-mail: mykola.ialovega@cea.fr
}

\begin{abstract}
.
The impact of helium (He) plasma exposure with He fluxes relevant for ITER and WEST on the near-surface microstructure of polycrystalline tungsten (W) is investigated by coupling transmission electron microscopy (TEM) analysis and thermal desorption spectrometry (TDS) measurements. The samples were exposed in the PSI-2 linear plasma device to $75 \mathrm{eV}$ He ions up to the fluence of $3 \times 10^{23} \mathrm{He} \mathrm{m}^{-2}$ with the surface temperature in the range $1053-1073 \mathrm{~K}$. The obtained He bubbles- enriched W samples are subsequently probed with sequences of low flux and low fluence $250 \mathrm{eV}$ deuterium (D) ion implantations and TDS measurements in an ultra-high-vacuum setup to study the effects of the near-surface morphology changes due to the helium irradiation on fundamental mechanisms of deuterium retention. The results obtained for two different nearsurface layer He bubbles morphologies revealed that the effects of He irradiation on $\mathrm{D}$ retention in $\mathrm{W}$ strongly depend on its subsequent thermal cycling. For annealing below $900 \mathrm{~K}$, deuterium retention is similar to the one measured in pristine W. In contrast, for annealing above $1150 \mathrm{~K}$, deuterium retention in the He bubbles enriched $\mathrm{W}$ is increased 3 to 8 -fold as compared to non-damaged W. Additionally, the deuterium desorption peak shifts from 540 to $450 \mathrm{~K}$. This increase of D trapping in the He bubbles enriched W annealed above $1150 \mathrm{~K}$ is presumably associated with a modification of the near-surface microstructure concurrent with an outgassing of He.
\end{abstract}

Keywords: Tungsten, Hydrogen trapping, Helium bubbles, Thermodesorption, Transmission electron microscopy 


\section{Introduction}

Investigations of hydrogen isotopes and helium retention in plasma facing components (PFC) that are exposed to various plasma conditions are important for future fusion devices such as ITER and DEMO. Tungsten (W) has been chosen as the plasma-facing material of the ITER divetor due to its favorable physical properties like low sputtering yield, high melting temperature and high thermal conductivity. However, in the deuterium/tritium phase of ITER, W PFC will experience incident particles flux composed of hydrogen isotopes (HI), helium (He), other impurities and neutrons. Their interaction with PFC may modify the retention properties of tungsten.

In the past years considerable work has been carried out to estimate the implantation and retention of $\mathrm{HI}$ and He in ITER. On the one hand [1,2], it was concluded, that without considering the effect of the presence of He in the bulk of polycrystalline tungsten PFC, the tritium inventory remains in tolerable limits and should not reach the $700 \mathrm{~g}$ safety limit in the ITER vacuum vessel. On the other hand, intensive He fluxes affect the PFC material causing erosion and damage formation on $\mathrm{W}$ surfaces as well as create damages in the $\mathrm{W}$ bulk. Highly porous structures, so-called W "fuzz" nanostructures, are formed when W is submitted to low energy He irradiation at temperature above $1100 \mathrm{~K}[3,4]$. At lower temperatures, undulating surface structures that depend on the grain orientation as well as numerous holes may appear on $\mathrm{W}$ surfaces $[5,6]$. Furthermore, helium irradiation affect the near-surface region of $\mathrm{W}$ PFC causing the formation of helium bubbles and dislocation loops [7]. It has been already shown that the presence of He bubbles in tungsten and other metals strongly modifies the HI retention, with a complex interplay of the $\mathrm{He} / \mathrm{D}$ kinetic energy ratio and flux ratio [8]. For He kinetic energy above $500 \mathrm{eV}$, displacement damage such as vacancies and dislocations are created during He irradiation resulting in an increase of $\mathrm{D}$ retention in $\mathrm{W}$ [9]. In contrast, for He kinetic energy below $500 \mathrm{eV}$ there is no displacement damage and it is generally measured a decrease of $\mathrm{D}$ retention in $\mathrm{W}$ [10]. This reduction of $\mathrm{D}$ retention in absence of displacement damage is currently explained by the presence of He bubbles. These He bubbles could act as a bulk diffusion barrier for deuterium and/or the He bubbles would formed interconnected pathways that ease D diffusion to the surface. Recently, Markel et al. [11] have used heavily damaged $\mathrm{W}$ to prepare a dense He implantation zone without He bubbles. They observed that $\mathrm{D}$ retention increases in the He implanted zone suggesting that vacancies, vacancy clusters and dislocations decorated with $\mathrm{He}$ are additional trapping sites. However, the local effect of He bubbles on D retention has not been measured up to now.

In the ITER divertor strike-points particle fluxes are expected to be of the order of $10^{24}$ ions $\mathrm{m}^{-2} \mathrm{~s}^{-1}$, and W PFC surface temperature to be about $1100 \mathrm{~K}$ [12]. Due to the low kinetic energy of the particles in the divertor region $(<100 \mathrm{eV})$, the implantation range of the incident helium ions is expected to be on the order of several nanometers and He bubbles may be created. Thus, the near surface layer of W PFC enriched with helium might have different retention properties than the bulk of W PFC. This conclusion provides the aim of this study i.e. to explore the effects of near-surface morphology change due to the low energy helium irradiation on $\mathrm{HI}$ retention in $\mathrm{W}$ and give more insight into the fundamental interaction of $\mathrm{D}$ and He induced defects in $\mathrm{W}$, in particular in case of He bubbles. The helium irradiation parameters are chosen to be as close as possible to ITER conditions, i.e. at high He flux (up to $2.3 \times 10^{22} \mathrm{He} \mathrm{m}^{-2} \mathrm{~s}^{-1}$ ) and high W PFC temperatures (up to $1073 \mathrm{~K}$ ). Such implantation conditions are also relevant for the $\mathrm{C} 4$ helium campaign in the WEST tokamak, where the particle fluxes in the divertor region are expected to be around $10^{21} \mathrm{He} \mathrm{m}^{-2} \mathrm{~s}^{-1}$.

In the present paper, the impact of ITER relevant helium irradiation on the $\mathrm{W}$ surface and near-surface layer is investigated by scanning electron microscopy and cross-sectional transmission electron microscopy analysis. Additionally, low energy and low flux deuterium implantation at room temperature is used as a probe, together with in situ thermo-desorption spectrometry (TDS), to investigate the fundamental mechanisms of HI retention in the He enriched near-surface layer. Finally, the effect of thermal sweep (cycling) on deuterium retention in the He enriched near-surface layer is investigated with TDS and discussed.

\section{Experiment}

Two polycrystalline tungsten samples (99.995\%, Toho Kinzoku Co. Ltd.) were mechanically polished and annealed at $1773 \mathrm{~K}$ in vacuum for $2 \mathrm{~h}$. They were exposed to a low-temperature helium plasma in the linear plasma device PSI-2 [13] in Jülich (Germany). The samples were biased at $100 \mathrm{~V}$, the typical incident helium kinetic energy was expected to be $75 \mathrm{eV}$ therefore below the $\mathrm{W}$ sputtering threshold energy by He [14]. Incident helium fluxes were estimated to be $2.3 \times 10^{22} \mathrm{He} \mathrm{m}^{-2} \mathrm{~s}^{-1}$ at $1053 \mathrm{~K}$ (high flux (HF) conditions) and $2.9 \times 10^{20} \mathrm{He} \mathrm{m}^{-2} \mathrm{~s}^{-1}$ at $1073 \mathrm{~K}$ (low flux (LF) conditions). Exposure time was $13 \mathrm{sec}$ in the HF case and $1034 \mathrm{sec}$ in the LF case to obtain an identical helium fluence of $3 \times 10^{23} \mathrm{He} \mathrm{m}^{-2}$ on both samples. Before switching on the plasma, the samples were preheated up to $1073 \mathrm{~K}(\mathrm{LF})$ or $1053 \mathrm{~K}$ (HF) by a resistive heater installed on the sample carrier under the sam- 
ples. In the case of the HF sample, the heating was turned off during the plasma exposure. For the LF case, the heating power was gradually reduced during the exposure in order to keep the sample temperature constant. Additional increase in temperature due to the plasma heating during exposure for both cases was well below $100 \mathrm{~K}$. After the exposure, the samples were cooled down to room temperature (RT) within a few minutes. Detailed information about the layout of the PSI-2 device, its parameters and operational conditions can be found in [13]. The main impurity content in PSI-2 (oxygen) is of the order of $0.1 \%$ [15].

$\mathrm{HF}$ and LF samples were then introduced into the ultra-high-vacuum setup CAMITER (base pressure < $2.3 \times 10^{-7} \mathrm{~Pa}$ ) in Marseille (France) for in situ deuterium implantation and TDS experiments $[16,17]$. Firstly, the surfaces of the samples were "cleaned" by an initial outgassing with a TDS ramp of $1 \mathrm{~K} \mathrm{~s}^{-1}$ up to $800-870 \mathrm{~K}$ in order to desorb loosely bound impurities such as water molecules and hydrocarbons. This step is usually performed in Marseille on all introduced samples prior to $\mathrm{D}$ implantation since it has been shown that this "cleaning" procedure allows to have reproducible $\mathrm{D}$ retention measurement at low $\mathrm{D}$ fluence, i.e. when the measured $\mathrm{D}$ retention is on the order of a monolayer $\left(10^{19} \mathrm{D} \mathrm{m}^{-2}\right)$ or less [17]. Note that the TDS range up to $800-850 \mathrm{~K}$ corresponds to the typical D retention temperature interval in pristine $\mathrm{W}$ and remains at least $200 \mathrm{~K}$ lower than the He irradiation temperature. Then, $D_{2}^{+}$ion implantation and subsequent TDS measurements up to $1200-1350 \mathrm{~K}$ were repeated 5 times (implantation-TDS experiments). Deuterium implantation was realized with an Omicron ISE 10 sputter ion gun at RT with flux of $1.7 \times 10^{16} \mathrm{D} \mathrm{m}^{-2} \mathrm{~s}^{-1}$ and fluence of $4.5 \times 10^{19} \mathrm{D} \mathrm{m}^{-2}$. The incident kinetic energy per deuterium ion of $250 \mathrm{eV} / \mathrm{D}$ is also below the $\mathrm{W}$ sputtering threshold [18]. The implantation depth of $250 \mathrm{eV} \mathrm{D}$ ions is $\sim 15 \mathrm{~nm}$ according to SRIM calculations [19]. A multiplexed Quadrupole Mass Spectrometer (QMS) was used to record simultaneously the outgassing of $\mathrm{HI}$ molecules, i.e. of $\mathrm{H}_{2}, \mathrm{HD}$ and $\mathrm{D}_{2}$, as well as He atoms during TDS. It was possible to distinguish between outgassing of $\mathrm{He}$ and $\mathrm{D}_{2}$ thanks to their different electron ionization energy thresholds. The QMS count rate signal at $\mathrm{m} / \mathrm{z}=4$ was recorded at two different electron energy, one below the ionisation threshold of $\mathrm{He}$ (only $\mathrm{D}_{2}$ contributes to the $\mathrm{m} / \mathrm{z}=4$ signal) and the other above the ionisation threshold of $\mathrm{He}$ (both $\mathrm{D}_{2}$ and He contribute to the $\mathrm{m} / \mathrm{z}=4$ signal). The He desorption rate was therefore deduced by subtraction of the $\mathrm{D}_{2}$ signal as determined for the electron energy below the ionization threshold of $\mathrm{He}$, and corrected for electron energy dependent ionization cross sections. Additionally, the $\mathrm{D}_{2}$ signal originating from the molybdenum sample holder was subtracted to ob- tain the sample $\mathrm{D}_{2}$ desorption rate. Statistical errors were propagated accordingly. Unfortunately, during the experiments on the LF sample, a problem of temperature control occured and the obtained TDS spectra present several desorption rate bumps related to temperature rate spikes in the deuterium desorption range. This makes the TDS data interpretation more difficult and thus the TDS spectra of deuterium is not shown for the LF case. Nevertheless, the time-integrated TDS spectra for the LF case remain suitable for deuterium retention and helium outgassing quantification.

The transmission electron microscopy (TEM) investigation allowed cross-sectional observation of the effects of helium plasma exposure in the near-surface layers of the samples. It was performed using TEM on thin laminae that were cut on both samples with the focused ion beam (FIB) technique. Scanning electron microscopy (SEM) allowed to observe the surface morphology of the samples after the helium irradiation.

\section{Results and discussion}

\subsection{Sample surface SEM observation and cross-sectional TEM analysis after the helium irradiation}

The surface morphology of the helium exposed tungsten changes significantly as compared to the non-exposed samples that has been shown earlier by Sakamoto et al. [5]. Figure 1 a) (resp. b)) shows the surface at different grains and c) (resp. d)) a close up within one grain of the LF (resp. HF) sample obtained by SEM after the helium irradiation. Helium irradiation in PSI-2 caused the appearance of holes of about 10 to $30 \mathrm{~nm}$ in diameters on the surfaces of both samples. This hole formation is observed on all grains of the samples (see figure 1 a) and b)) and thus, does not depend on the grain orientation. Considering the sputtering yield of oxygen on $\mathrm{W}$ to be $\sim 2 \times 10^{-2}[18,20,21]$, it is estimated that about $40 \%$ of $\mathrm{W}$ atoms of the first surface plane will be sputtered because of impurities in PSI2 plasma in the LF and HF samples. This is not sufficient to explain the observed holes. However, the present SEM observations are consistent with the ones presented in [4] because the He irradiation surface temperature is at the threshold for nanostructure formation $(\sim 1050 \mathrm{~K})$. Molecular dynamics simulations done by Sefta et al. [22] have shown that holes (or so-called craters) formation on the $\mathrm{W}$ surface occurs in this temperature range because of the growth and pressure evolution of helium bubbles below the surface. The accumulation of helium in bubbles results into bubble growth towards the free surface. Overpressurized bubbles may undergo pressure relief through surface deformation by cratering and further 

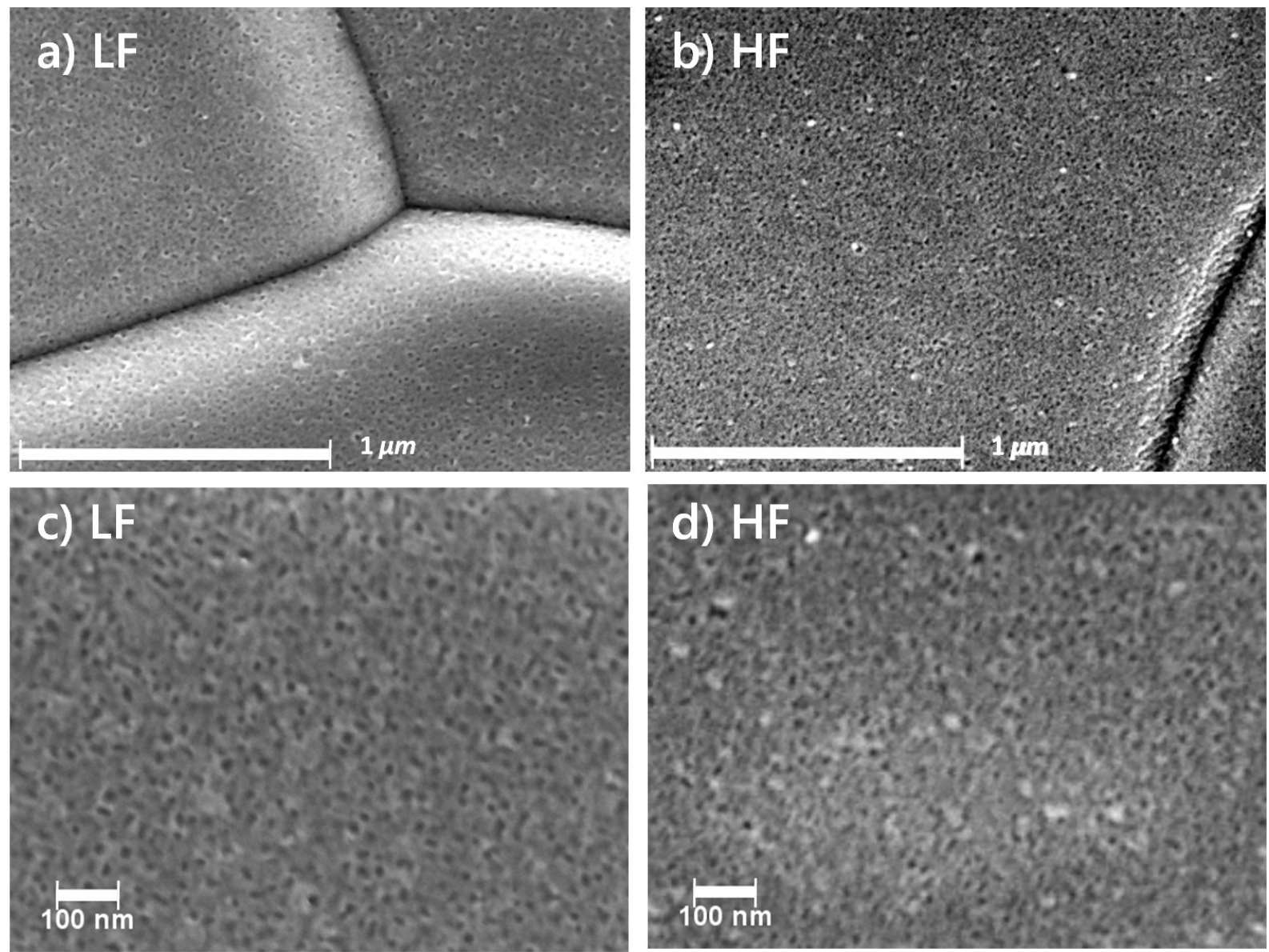

Figure 1. Scanning electron microscopy images of tungsten irradiated with $75 \mathrm{eV}$ helium ions at a fluence of $3 \times 10^{23} \mathrm{He} \mathrm{m}{ }^{-2}$ before the set of deuterium implantation-TDS experiments. a) and c) for low flux (LF) conditions i.e. $2.9 \times 10^{20} \mathrm{He} \mathrm{m}^{-2} \mathrm{~s}^{-1}$ at $1073 \mathrm{~K}$. b) and d) for high flux (HF) conditions i.e. $2.3 \times 10^{22} \mathrm{He} \mathrm{m}^{-2} \mathrm{~s}^{-1}$ at $1053 \mathrm{~K}$. A closer view on one of the grains for c) LF and d) $\mathrm{HF}$ conditions.
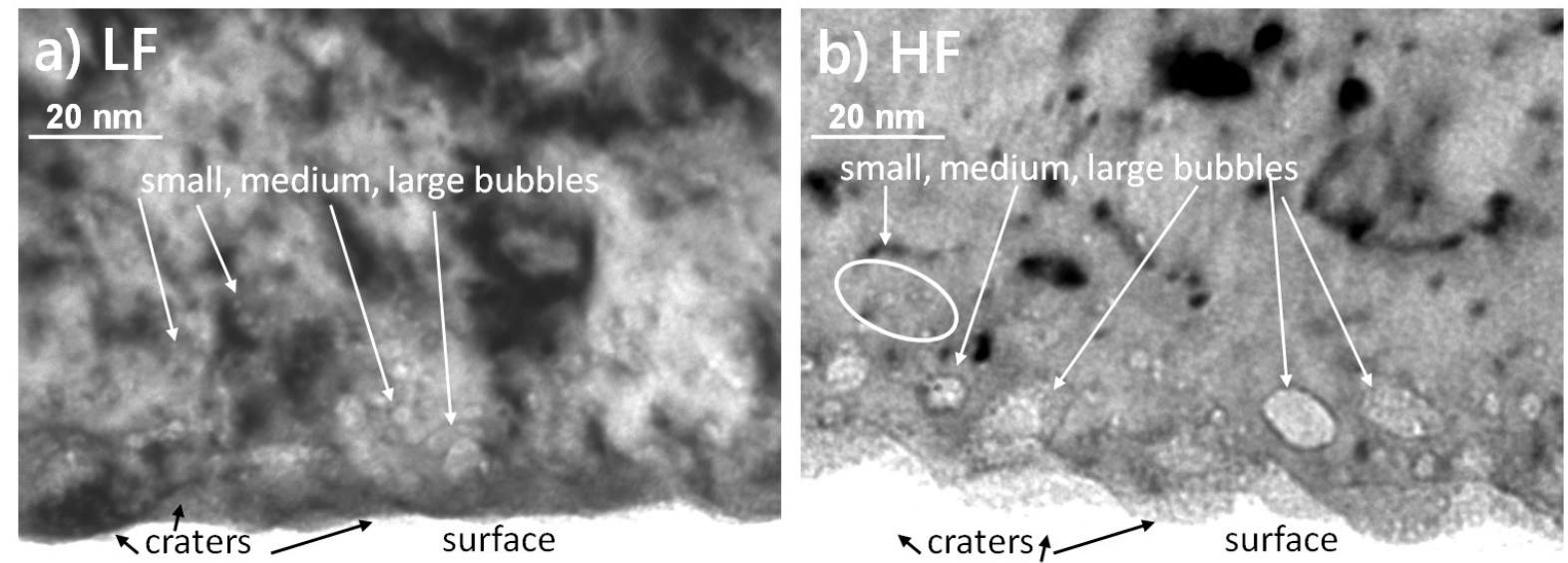

Figure 2. Transmission electron images of tungsten irradiated with $75 \mathrm{eV}$ helium ions at a fluence of $3 \times 10^{23} \mathrm{He} \mathrm{m}^{-2}$ at different fluxes of a) $2.9 \times 10^{20} \mathrm{He} \mathrm{m}^{-2} \mathrm{~s}^{-1}$ at $1073 \mathrm{~K}$ (low flux (LF)) and b) $2.3 \times 10^{22} \mathrm{He} \mathrm{m}^{-2} \mathrm{~s}^{-1}$ at $1053 \mathrm{~K}$ (high flux (HF)) before the set of deuterium implantation-TDS experiments.

helium release. He bubble growth occurs in our samples as shown in figure 2 .

Figure 2 shows the typical TEM micrographs of tungsten irradiated with $\mathrm{He}$ in a) LF at $1073 \mathrm{~K}$ and b) $\mathrm{HF}$ at $1053 \mathrm{~K}$ conditions before the set of deuterium implantation-TDS experiments. After the helium 
plasma exposure at 1053-1073 K, helium bubbles of different size are observed in the bulk of both tungsten samples. In the LF case, few large helium bubbles $(\mathrm{d} \sim 10 \mathrm{~nm})$ and numerous smaller bubbles are present in the near-surface region. Analysis of the laminae showed that there are 2 times more large bubbles formed in the HF case than in the LF case and they are mostly located in the first $20 \mathrm{~nm}$ below the surface. The exposure time is much shorter in the HF case $(13 \mathrm{sec})$ as compared to the LF case $(1034 \mathrm{sec})$, thus, helium trapping at pre-existing natural defects through diffusion is reduced in the HF case. On the other hand, the possibility of helium self-trapping is expected to increase as the helium density in the implantation zone is higher since the He flux has been increased at constant temperature in the HF case. Thus, larger helium bubbles close to the surface can be formed in the HF case. The small bubbles $(\mathrm{d} \sim 1-2 \mathrm{~nm})$ are distributed deeper than the large ones in both samples. These depths are well beyond the He implantation range, which is around $2 \mathrm{~nm}$ according to SRIM calculations. During He irradiation at 1053-1073 K, helium atoms are highly mobile in tungsten and, in addition to self-trapping, they can be trapped at natural defects such as vacancies [23] and dislocations far deeper than the implantation range [7].

\subsection{Thermodesorption analysis}

SEM and cross-sectional TEM analysis showed that He irradiation in PSI-2 creates a He bubbles enriched near-surface layer of $\sim 40 \mathrm{~nm}$ in $\mathrm{LF}$ and $\mathrm{HF}$ samples. In particular, the largest He bubbles are located in the first $20 \mathrm{~nm}$ in both samples. The effect of this near-surface layer of large He bubbles on hydrogen isotopes retention is now probed with low flux - low fluence deuterium implantation which kinetic energy $(250 \mathrm{eV} / \mathrm{D})$ is set to allow a $\sim 15 \mathrm{~nm}$ deep implantation without further defect creation.

Figure 3 a) shows the amount of outgassed helium for LF and HF samples at each step of the experimental campaign: initial TDS outgassing ("cleaning" in the following) and sequence of deuterium implantationTDS experiments. Initial "cleaning" up to $800-$ $870 \mathrm{~K}$ induced a small outgassing of helium of $(4.2 \pm$ $0.6) \times 10^{18} \mathrm{He} \mathrm{m}^{-2}(\mathrm{LF})$ and $(2.6 \pm 0.4) \times 10^{18} \mathrm{He} \mathrm{m}^{-2}$ (HF). The majority of He outgassing occurs during the first TDS ramp up to 1170 (LF) and $1250 \mathrm{~K}$ $(\mathrm{HF})$ where $(3.8 \pm 0.2) \times 10^{19} \mathrm{He} \mathrm{m}^{-2}(\mathrm{LF})$ and $(1.9 \pm$ $0.2) \times 10^{19} \mathrm{He} \mathrm{m}^{-2}(\mathrm{HF})$ are measured. The total amount of helium desorbed during the initial TDS "cleaning" and all implantation-TDS experiments is around $5.0 \times 10^{19} \mathrm{He} \mathrm{m}^{-2}(\mathrm{LF})$ and $2.7 \times 10^{19} \mathrm{He} \mathrm{m}^{-2}$ (HF) or $0.017 \%(\mathrm{LF})$ and $0.009 \%$ (HF) respectively to the initial helium irradiation fluence. These results suggest that helium is still retained in the samples, presumably in the numerous small and large bubbles. It could eventually be released at higher temperatures which should be checked in future works.

Figure $3 \mathrm{~b}$ ) shows the amount of outgassed deuterium, so-called deuterium retention, for the implantation-TDS experiments. The first implantationTDS sequence is performed on $\mathrm{W}$ samples when most of helium is still present in the near-surface region and resulted in a small amount of deuterium trapped in both samples: about $(0.7 \pm 1.4) \times 10^{18} \mathrm{D} \mathrm{m}^{-2}(\mathrm{LF})$ and $(1.6 \pm 2.2) \times 10^{18} \mathrm{D} \mathrm{m}^{-2}(\mathrm{HF})$ is released during the TDS. These deuterium quantities are smaller than the He desorbed during the initial TDS and similar to deuterium retention of about $1.7 \times 10^{18} \mathrm{D} \mathrm{m}^{-2}$ obtained on non-damaged polycrystalline $\mathrm{W}$ samples from the same manufacturer and from samples produced by ALMT with similar annealing procedures [17]. The typical TDS spectra for the case of non-damaged polycristalline $\mathrm{W}$ sample is the same for both manufacturers and an example for the manufacturer used in the present study is shown in $3 \mathrm{c}$ ) (grey dots): it consists in a single deuterium desorption peak starting at $320 \mathrm{~K}$, peaking at $450 \mathrm{~K}$ and having a desorption tail up to $700 \mathrm{~K}$. In contrast, the deuterium desorption peak of the first deuterium implantation-TDS experiment for the He irradiated HF sample is centered at a higher temperature $(\sim 540 \mathrm{~K}$, figure $4 \mathrm{c}))$ but is still within the non-damaged desorption range. The shift to higher temperature of the deuterium desorption peak following He irradiation could be the result of: an increased D trapping energy, an increased D diffusion length and/or an increased stability of D atoms at the modified surface. A modification of the surface adsorption properties could be induced by the presence of oxygen impurities in PSI-2, indeed. However, Whitten and Gomer [24] have shown that an increase of oxygen surface coverage shifts the position of the desorption peak to lower temperature, i.e. the opposite of our observation after He irradiation in PSI-2. Besides, an increased $\mathrm{D}$ diffusion length would result in an increase of $\mathrm{D}$ retention as compared to pristine $\mathrm{W}$, which we do not observe. Therefore, our observation that the $\mathrm{D}$ desorption peak shifts to higher temperature by $\sim 100 \mathrm{~K}$ after He irradiation should indicate that the presence of He bubbles increases slightly the deuterium trapping energy. It can be noted that this $\mathrm{D}$ desorption peak corresponding to the traps in the He bubbles enriched near-surface layer is similar to the first He desorption peak from the initial TDS "cleaning" (figure $4 \mathrm{a}$ ) and b)). However, the fact that the He desorption rate in the $540 \mathrm{~K}$ "cleaning peak" is 10 times smaller than the $\mathrm{D}$ desorption rate after $\mathrm{D}$ implantation in the cleaned sample prevents to conclude on a link between these $\mathrm{He}$ and $\mathrm{D}$ desorption peaks.

Figures 3 a), 4 a) and 4 b) show that, for 


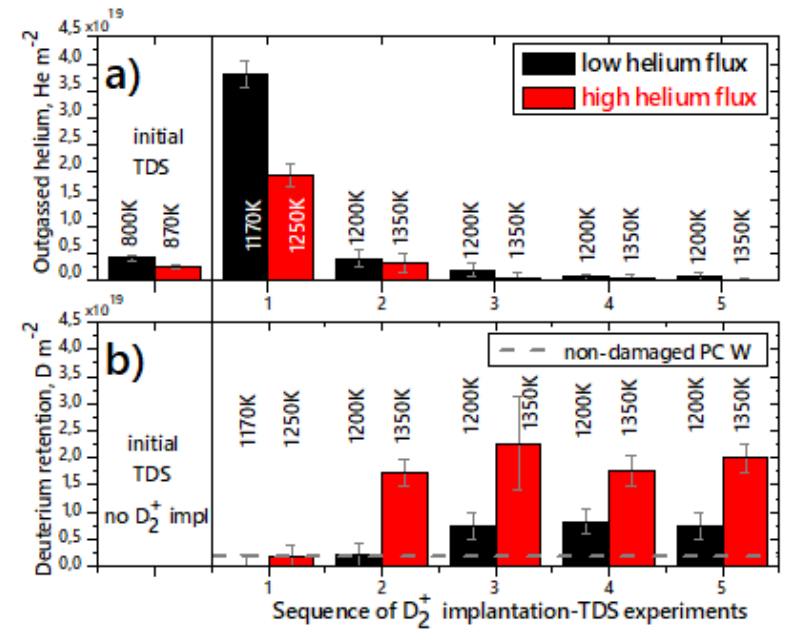

Figure 3. Thermo-Desorption Spectrometry results for two tungsten samples pre-irradiated in 75 eV helium ions: at a same fluence of $3 \times 10^{23} \mathrm{He} \mathrm{m}^{-2}$ but at different fluxes of $2.9 \times 10^{20} \mathrm{He} \mathrm{m}^{-2} \mathrm{~s}^{-1}$ at $1073 \mathrm{~K}$ (low flux) and $2.3 \times 10^{22} \mathrm{Hem}^{-2} \mathrm{~s}^{-1}$ at $1053 \mathrm{~K}$ (high flux). a) Outgassed amount of $\mathrm{He}$ and b) outgassed amount of deuterium (so-called deuterium retention) for each $D_{2}^{+} 500 \mathrm{eV}$ implantation-TDS sequence (each implantation fluence is $4.5 \times 10^{19} \mathrm{D} \mathrm{m}^{-2}$ ). Temperatures above each bar indicate the highest temperature reached during each TDS cycle. Grey dashed line represents the deuterium retention for the non-damaged polycristalline (PC) W sample.
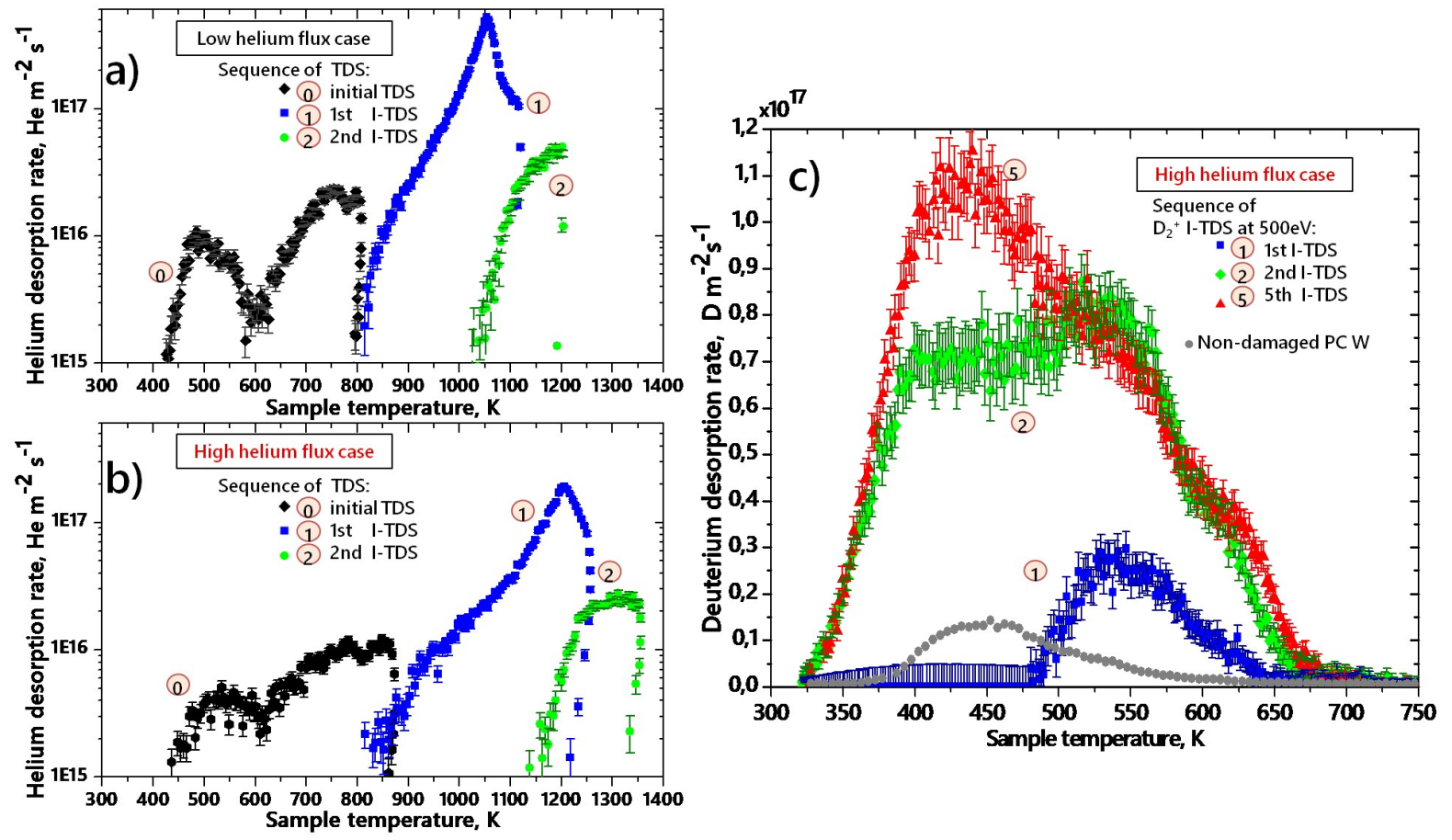

Figure 4. Thermal desorption spectra (TDS) for two tungsten samples pre-irradiated in $75 \mathrm{eV}$ helium ions: at a same fluence of $3 \times 10^{23} \mathrm{He} \mathrm{m}^{-2}$ but at different fluxes of $2.9 \times 10^{20} \mathrm{He} \mathrm{m}^{-2} \mathrm{~s}^{-1}$ at $1073 \mathrm{~K}$ (low flux (LF)) and $2.3 \times 10^{22} \mathrm{He} \mathrm{m}^{-2} \mathrm{~s}^{-1}$ at $1053 \mathrm{~K}$ (high flux (HF)). TDS spectra of helium for the a) LF case and b) for the HF case. c) TDS spectra of deuterium for the HF sample. Circled numbers denote the sequence number in the deuterium implantation-TDS (I-TDS) experiment (each implantation fluence is $4.5 \times 10^{19} \mathrm{D} \mathrm{m}^{-2}$ ). In case of the initial TDS up to $800 \mathrm{~K}(\mathrm{LF})$ and $850 \mathrm{~K}(\mathrm{HF})$ no deuterium was implanted. Grey dots represent the typical TDS spectra for the non-damaged polycristalline (PC) W sample.

both samples, He outgassing is maximal in the thermodesorption phase of the 1st D implantationTDS sequence well after the desorption of deuterium and reaching a peak of outgassing rate at $1050 \mathrm{~K}$ (resp. $1200 \mathrm{~K}$ ) in the LF (resp. HF) case. About 3.8 (resp. 1.9) $\times 10^{19} \mathrm{He} \mathrm{m}^{-2}$ is outgassed in this 
single temperature sweep, ten times more than in the next implantation-TDS sequences. The maximal He outgassing is accompanied with a drastic change in the deuterium retention and deuterium TDS spectra for the subsequent (2nd) D implantation-TDS sequence (figure $4 \mathrm{c})$ ). The next three implantation-TDS sequences up to $1200-1350 \mathrm{~K}$ consolidate the evolution of deuterium retention and TDS spectra, concurrent with a small He outgassing. The deuterium desorption peak shifted to $450 \mathrm{~K}$, with a shape similar of nondamaged $\mathrm{W}$ but with a $\mathrm{D}$ retention increased up to 8 times: deuterium retention rapidly saturates for each D implantation-TDS sequence around $0.8 \times 10^{19} \mathrm{D} \mathrm{m}^{-2}$ ( $17 \%$ of the deuterium fluence) for LF and around $2 \times 10^{19} \mathrm{D} \mathrm{m}^{-2}$ (41\% of the deuterium fluence) for HF.

At first glance, it appears that the lesser helium remains in the samples, the more deuterium is trapped. This suggests that deuterium may occupy the emptied trapping sites of the He bubbles enriched near-surface layer. But this does not explain the fact that for the lesser helium release in the HF case, the deuterium trapping is higher than in the LF case. Actually, the amount of $\mathrm{D}$ retention in the HF sample is on a par with the He outgassing while, for the LF sample, the $\mathrm{D}$ retention is 5 times smaller than the outgassed He. The difference of behavior in terms of $\mathrm{D}$ retention for low flux (LF) and high flux (HF) samples may be related with the higher density of the large helium bubbles in the HF case (see figure 2) and the helium content that is inside the bubbles. Since the total helium content in both samples is unknown at the moment, it is not possible to conclude on the density of $\mathrm{He}$ inside the bubbles. However, a preliminary comparison of laminae cut on different grains on both samples before and after the implantation-TDS experiments show the disappearance of the small $\mathrm{He}$ bubbles in the first few nanometers from the surface while slightly larger bubbles remain in the near-surface layer. These preliminary TEM observations support the following interpretation of our results in the frame of the literature work for He irradiation with kinetic energy below the displacement damage threshold.

After He irradiation and for annealing below the $\mathrm{He}$ irradiation temperature, D diffusion is slowed down by the presence of numerous small He bubbles in the few nanometer layer below the surface, which binding energy is slightly higher than natural defects in pristine $\mathrm{W}$, thus limiting $\mathrm{D}$ retention. For annealing above the He irradiation temperature, small He bubbles diffuse and disappear in the first few nanometer layer below the surface leaving a pristine $\mathrm{W}$ decorated with larger $\mathrm{He}$ bubbles where $\mathrm{D}$ can diffuse and bind to the bubbles periphery, thus increasing the D retention. Indeed, DFT and MD studies [25, 26, 27] have shown that deuterium atoms bind around He- vacancy clusters complexes and $\sim 2 \mathrm{~nm}$ He bubbles with a large binding energy range of $0.8-2.0 \mathrm{eV}$ consistent with our broad D desorption peak. Our interpretation is also consistent with the following observation: a higher He release for the LF sample but a higher D retention for the HF sample. For long He irradiation at low flux (LF sample), a greater number of small He bubbles than large He bubbles is obtained because of greater time allowed for He diffusion and a smaller He density. These small bubbles being more mobile, they will lead to a high He release upon annealing. In contrast, a short high flux He irradiation (HF sample) will lead to a stronger self-trapping favoring large He bubbles over small He bubbles. Thus, less He release and more D retention. Of course, more sophisticated statistical analysis on density and size of the bubbles is necessary and will be the subject of future systematic studies. In particular, we plan to investigate the evolution of the microstructure at each step of the implantation-TDS experiments presented here. Nevertheless, the current experimental results already highlight that the helium content in the samples and the helium bubbles morphology and their density are important parameters responsible for the modification of hydrogen isotopes retention in tungsten.

\section{Summary and perspectives}

In this paper, thermodesorption spectrometry technique combined with transmission electron microscopy observations were used to study deuterium retention in polycrystalline tungsten exposed to helium plasma. Irradiation by helium in conditions relevant to ITER and WEST $\left(3 \times 10^{23} \mathrm{He} \mathrm{m}^{-2}\right.$ at $\left.1053-1073 \mathrm{~K}\right)$ caused the appearance of helium bubbles of different size near the surface. He bubbles located within $20 \mathrm{~nm}$ of the surface are probed by a set of sequential low fluence deuterium ion implantation/desorption experiments up to 1200 $1350 \mathrm{~K}$. The obtained TDS spectra and deuterium retention results indicate an important effect of the thermal cycling of He-irradiated $\mathrm{W}$ on deuterium retention. At low deuterium fluence, the deuterium retention in the He bubbles enriched near-surface layer is initially similar than for pristine $\mathrm{W}$ but with a slightly higher binding energy. After thermal cycling above the He irradiation temperature, the $\mathrm{D}$ binding energy is lowered to a similar value range as for pristine $\mathrm{W}$ but the deuterium retention is increased 3 to 8 -fold as compared to non-damaged polycrystalline $\mathrm{W}$. The modification of D retention upon thermal cycling appear to be linked with the density of various He bubbles. We rationalize the increase of deuterium retention upon annealing above the He irradiation temperature, with the evolution of the helium bubbles morphology distribution in 
tungsten following thermal cycling.

In the future development of our work, we will determine the total helium content in the samples and focus on structural analysis of He bubbles and surface morphology evolution with stepwise thermal cycling.

\section{Acknowledgement}

The project leading to this publication has received funding from the Excellence Initiative of Aix-Marseille University - A*Midex, a French "Investissements d'Avenir" programme as well as from the ANR under grant ANR-18-CE05-12.

This work has been also carried out within the framework of the French Federation for Magnetic Fusion Studies (FR-FCM) and of the EUROfusion Consortium and has received funding from the Euratom research and training program 2014-2018 and 2019-2020 under grant agreement No633053. The views and opinions expressed herein do not necessarily express those of the European Commission.

The electron microscopy analysis was performed at FSCM-CP2M laboratory of Aix-Marseille University, France. In particular, we are grateful to Cabié M. and Campos A.

We gratefully acknowledge the helpful discussions with Dr. A. De Backer, Dr. J. Mougenot and Dr. M.-F. Barthe.

[1] Roth J, Tsitrone E, Loarte A, Loarer T, Counsell G, Neu R, Philipps V, Brezinsek S, Lehnen M, Coad P, Grisolia C, Schmid K, Krieger K, Kallenbach A, Lipschultz B, Doerner R, Causey R, Alimov V, Shu W, Ogorodnikova O, Kirschner A, Federici G and Kukushkin A 2009 Journal of Nuclear Materials 390-391 1 - 9 ISSN 00223115 proceedings of the 18th International Conference on Plasma-Surface Interactions in Controlled Fusion Device URL http://www.sciencedirect.com/science/ article/pii/S0022311509000506

[2] Hodille E A, Bernard E, Markelj S, Mougenot J, Becquart C S, Bisson R and Grisolia C 2017 Physica Scripta T170 014033 URL https://doi.org/10.1088\%2F1402-4896\% 2Faa8787

[3] De Temmerman G, Bystrov K, Zielinski J J, Balden M, Matern G, Arnas C and Marot L 2012 Journal of Vacuum Science \& Technology A 30041306 (Preprint https://doi.org/10.1116/1.4731196) URL https:// doi.org/10.1116/1.4731196

[4] Kajita S, Sakaguchi W, Ohno N, Yoshida N and Saeki T 2009 Nuclear Fusion 49095005 URL https://doi.org/ 10. $1088 \% 2 \mathrm{~F} 0029-5515 \% 2 \mathrm{~F} 49 \% 2 \mathrm{~F} 9 \% 2 \mathrm{~F} 095005$

[5] Sakamoto R, Bernard E, Kreter A and Yoshida N 2016 Nuclear Fusion 57016040 URL https://doi.org/10. 1088\%2F $1741-4326 \% 2 \mathrm{~F} 57 \% 2 \mathrm{~F} 1 \% 2 \mathrm{~F} 016040$

[6] Sakamoto R, Bernard E, Kreter A, Martin C, Pégourié B, Pieters G, Rousseau B, Grisolia C and Yoshida N 2017 Physica Scripta T170 014062 URL https://doi.org/ $10.1088 \% 2 \mathrm{~F} 1402-4896 \% 2 \mathrm{Faa} 93 \mathrm{a} 2$

[7] Bernard E, Sakamoto R, Tokitani M, Masuzaki S, Hayashi H, Yamada H and Yoshida N 2017 Journal of Nuclear Materials 48424 - 29 ISSN 00223115 URL http://www.sciencedirect.com/science/ article/pii/S0022311516306560

[8] Zhou Q, Azuma K, Togari A, Yajima M, Tokitani M,
Masuzaki S, Yoshida N, Hara M, Hatano Y and Oya Y 2018 Nuclear Materials and Energy 1676 - 81 ISSN 2352-1791 URL http://www.sciencedirect.com/ science/article/pii/S2352179117301606

[9] Iwakiri H, Morishita K and Yoshida N 2002 Journal of Nuclear Materials 307-311 135 - 138 ISSN 00223115 URL http://ww..sciencedirect.com/science/ article/pii/S0022311502011789

[10] Miyamoto M, Nishijima D, Ueda Y, Doerner R, Kurishita H, Baldwin M, Morito S, Ono K and Hanna J 2009 Nuclear Fusion 49065035 URL https://doi.org/10. $1088 \% 2 \mathrm{~F} 0029-5515 \% 2 \mathrm{~F} 49 \% 2 \mathrm{~F} 6 \% 2 \mathrm{~F} 065035$

[11] Markelj S, Schwarz-Selinger T and Založnik A 2017 Nuclear Fusion $\mathbf{5 7} 064002$ URL https://doi.org/10. 1088\%2F $1741-4326 \% 2 \mathrm{Faa} 6 \mathrm{~b} 27$

[12] Pitts R, Carpentier S, Escourbiac F, Hirai T, Komarov V, Lisgo S, Kukushkin A, Loarte A, Merola M, Naik A S, Mitteau R, Sugihara M, Bazylev B and Stangeby P 2013 Journal of Nuclear Materials 438 S48 - S56 ISSN 0022-3115 proceedings of the 20th International Conference on Plasma-Surface Interactions in Controlled Fusion Devices URL http://www.sciencedirect.com/ science/article/pii/S0022311513000160

[13] Kreter A, Brandt C, Huber A, Kraus S, Möller S, Reinhart M, Schweer B, Sergienko G and Unterberg B 2015 Fusion Science and Technology 68 8-14

[14] Ferroni F, Hammond K D and Wirth B D 2015 Journal of Nuclear Materials 458419 - 424 ISSN 00223115 URL http://www.sciencedirect.com/science/ article/pii/S0022311514010332

[15] Schmitz J, Litnovsky A, Klein F, Wegener T, Tan X, Rasinski M, Mutzke A, Hansen P, Kreter A, Pospieszczyk A, Möller S, Coenen J, Linsmeier C, Breuer U, Gonzalez-Julian J and Bram M $2018 \mathrm{Nu}$ clear Materials and Energy 15220 - 225 ISSN 23521791 URL http://www.sciencedirect.com/science/ article/pii/S2352179117301023

[16] Hodille E, Ghiorghiu F, Addab Y, Založnik A, Minissale M, Piazza Z, Martin C, Angot T, Gallais L, Barthe M F, Becquart C, Markelj S, Mougenot J, Grisolia C and Bisson R 2017 Nuclear Fusion 57076019 URL https://doi.org/10.1088\%2F1741-4326\%2Faa6d24

[17] Bisson R, Markelj S, Mourey O, Ghiorghiu F, Achkasov K, Layet J M, Roubin P, Cartry G, Grisolia C and Angot T 2015 Journal of Nuclear Materials 467432 - 438 ISSN 0022-3115 URL http://www.sciencedirect.com/ science/article/pii/S0022311515301148

[18] 2001 Atomic and Plasma-Material Interaction Data for Fusion (Atomic and Plasma-Material Interaction Data for Fusion no 7/B) (Vienna: INTERNATIONAL ATOMIC ENERGY AGENCY) URL https://www.iaea.org/publications/4709/ atomic-and-plasma-material-interaction-data-for-fusion

[19] Ziegler J F, Ziegler M and Biersack J 2010 Nuclear Instruments and Methods in Physics Research Section B: Beam Interactions with Materials and Atoms 2681818 - 1823 ISSN 0168-583X 19th International Conference on Ion Beam Analysis URL http://www.sciencedirect. com/science/article/pii/S0168583X10001862

[20] Eckstein W 2002 Calculated sputtering, reflection and range values (ipp 9/132)

[21] Hechtl E, Eckstein W, Roth J and Laszlo J 1991 Journal of Nuclear Materials 179-181 290 - 293 ISSN 0022-3115 URL http://www.sciencedirect.com/ science/article/pii/002231159190083J

[22] Sefta F, Juslin N and Wirth B D 2013 Journal of Applied Physics 114243518 (Preprint https:// doi.org/10.1063/1.4860315) URL https://doi.org/ 10.1063/1.4860315

[23] Becquart C and Domain C 2007 Nuclear Instruments 
and Methods in Physics Research Section B: Beam Interactions with Materials and Atoms 25523 - 26 ISSN 0168-583X computer Simulation of Radiation Effects in Solids URL http://www.sciencedirect.com/science/ article/pii/S0168583X06010585

[24] Whitten J and Gomer R 1998 Surface Science 40916 - 26 ISSN 0039-6028 URL http://www.sciencedirect.com/ science/article/pii/S0039602898001885

[25] Becquart C and Domain C 2009 Journal of Nuclear Materials 386-388 109 - 111 ISSN 0022-3115 fusion Reactor Materials URL http://www.sciencedirect. com/science/article/pii/S0022311508008179

[26] Bergstrom Z J, Cusentino M A and Wirth B D 2017 Fusion Science and Technology $\mathbf{7 1}$ 122-135 (Preprint https://doi.org/10.13182/FST16-121) URL https:// doi.org/10.13182/FST16-121

[27] Yang L and Wirth B D 2018 Journal of Applied Physics 123 215104 (Preprint https://doi.org/10.1063/1.5027805) URL https://doi.org/10.1063/1.5027805 